INTERNATIONAL JOURNAL OF RESEARCHES IN BIOSCIENCES, AGRICULTURE AND TECHNOLOGY (C) VISHWASHANTI MULTIPURPOSE SOCIETY (Global Peace Multipurpose Society) R. No. MH-659/13(N) www.vmsindia.org

\title{
STUDIES ON BIODIVERSITY OF ZOOPLANKTON IN KASS LAKE DURING RAINY AND WINTER SEASONS
}

\author{
P.P.Yadav \\ S.M. Dr. Bapuji Salunkhe College, Miraj. (Maharashtra), 416410 \\ Pradip.yadav51@yahoo.com
}

\begin{abstract}
:
Satara city is a well known historical place situated at the foot hills of Sahyadri mountains. Around 25 Kmupon the mountain, away towards the western side of Satara, there is a natural lake available, invented by the Britishers and constructed. Water which was accumulated by the natural percolations is the potable water. This water is brought to the Satara city by the Britishers, by using the excellent technique of siphoning. This lake is full with biodiversity, rich with flora and fauna. So I have choosen this lake for mypresent,study.

The qualitative analysis of Zooplankton of the lake indicates seventeen species durinboth rainy and winter seasons. The major groups of Zooplankton in discending order are protozoa and arthropoda. The highest density of zooplankton was noted during rainy season where as it decreased to winter. Of the seventeen zooplanktonic species seven from protozoa, one from each porifera, cladocera, ostracoda and mollusca, four from arthropoda, few fishes and different larval stages of frog from amphibian are recorded. Simultaneously physico-chemical parameters such as physical appearance, atmospheric and surface temperature, $\mathrm{pH}$, chloride, ammonia nitrate, Hardness, CO2,Iron, Fluoride, DO and Solids values were recorded. All the values of physico-chemical parameters showed variations during rainy and winter seasons.
\end{abstract}

\section{Introduction:}

The global aquatic system contains different organisms which are dependent on the substratum or free from it. All type of aquatic eco-systems except for fast moving rivers contain planktonic organisms. In any water body along with the large animals and plants smaller microscopic phytoplanktons and zooplanktons occurs. The planktons have great significance in biology of aquatic ecosystem as they provide nourishment to aqutic organis ms. The planktons form the base of food pyramide. There is no balanced ecosystem without planktons in an aquatic ecosystem. They form an important constituent of the food of young ones of many fishes as well as other organisms. This indicates that in aquatic systems planktons are essential links in the food chain. Both zooplankton and phytoplankton constitute a vital link in the aquatic food chain. While phytoplankton play phenomenal role in the biosynthesis of organic material, the zooplankton, an important component of secondary production, provide a link between the producers and consumers.

The values of physicochemical parameters always vary with the density of the planktons. The seasonal variation in the values of these parameters is also related to the changes in the growth of the planktons. The phytoplanktons constitutes $95 \%$ of the total marine plant production (babu,2001) so they form a vital source of energy of the first tropical tier and also serve as a direct source of food to several aquatic animals. The zooplankton, an important component of secondary production, provide a link between producers and secondary consumers. The fry or juveniles of aquatic organisms first feed on the phytoplanktons because of direct gain of energy and ease of digestion. This chain of food ingredients further accelerates the growth of juvenile forms of aquatic organisms. The fishery is directly correlated to the plankton production and upwelling of sea Yeragi (1997). The fluctuation in fishery is mainly due to the variation of plankton both qualitatively and quantitatively. Thus importance of study of zooplankton lies in understanding the productivity of the aquatic system. The' KAAS' lake is much popular for its variety of biodiversity throughout the year, because of abundant availability of primary production. The present study related to evaluate the total population density of zooplankton species in tropical lake KAAS during rainy and winter season and also to estimate the physicochemical parameters and biological characteristics of same lake.

\section{Material and Methods: \\ Study Area:}

The late taken up for the present study is located in the Western Ghat region $25 \mathrm{~km}$ away from Satara City. This lake is called 'KAAS' lake according to name of the village nearest to it i.e. 'kaasegoan'.It is an open lake fully exposed to the atmosphere and surrounded by high trees. It was constructed during British period.It has following parameters. Name of the lake-'KAAS LaKE', Location=Near KAASGOAN. (Tal. And Dist.SATARA), Total Area-7.123sq. km, Height of Water level-1125.58 meter, Depth of water- 
1123.45 ,

1122.38meter,Deadstock

Level of storage-

level-

1115.53meter,Tap water level-1108.39 meter, Total water level-30.3Lac Cubic-ft, Storage of Useful water-26.8Lac Cubic-ft, Dead stock water-3.5Lac Cubic-ft, Type of water releasing-Stone Waste Wear, Total Length of Lake $7 \mathrm{~km} \quad[21 \mathrm{~km}$. constructed+6km.door.], Daily water consumtion-60.0Lac Cubic-ft.

\section{Collection of water Samples:-}

The surface water was collected in bottle of one liter capacity separately from five different places.It was filtered through a No.14 blotting paper. Collected macro-organism with the help of hand net and the samples and organism were brought in the laboratory were transferred to settling chamber and kept for 24 hours after adding a few drops of formalin. Then taking a drop of water with the glass dropper on a clean and dry slide and place the cover slip on it. Remove excess of water with the help of blotting paper and observed under the low power of microscope.

Observations:-

Under the microscope few micro-organisms were seen. For getting more organisms large quantity of sample was centrifuged and the supernatant was removed. A drop of sediment was taken on the slide and observed the body movement of the organism under the microscope. Then sketches and figures of the zooplankton were done. To study detailed structure of zooplankton.A drop of glacial acetic acid was used for cessation of the movement of organisms. The organism get fixed due to glacial acetic acid. This procedure was repeated 2-3 times and recorded different types of forms as well as the list of organisms according to their phylum was prepared which as follows.

Table No. 1. :

\begin{tabular}{|c|c|l|}
\hline $\begin{array}{c}\text { Sr. } \\
\text { No. }\end{array}$ & Phylum & \multicolumn{1}{|c|}{$\begin{array}{c}\text { Name Of The } \\
\text { Zooplankton }\end{array}$} \\
\hline 1 & Protozoa & $\begin{array}{l}\text { Euglena,Paramecium } \\
\text { caudatum,Vorticella } \\
\text { campanula,V. microstoma. }\end{array}$ \\
\hline 2 & Porifera & Spongilla. \\
\hline 3 & Cladocera & Daphnia sp. \\
\hline 5 & Arthropoda & $\begin{array}{l}\text { Mosquito larvae, water } \\
\text { bugs, may fly, nymph, } \\
\text { culex pupa, Caddisfly } \\
\text { larva. }\end{array}$ \\
\hline 6 & Mollusca & Lymnea stagnalis. \\
\hline 7 & Fishes & $\begin{array}{l}\text { Few fishes are also } \\
\text { observed. }\end{array}$ \\
\hline 8 & Amphibia & $\begin{array}{l}\text { Different larval stages of } \\
\text { frog. }\end{array}$ \\
\hline
\end{tabular}

Water samples were collected using glass bottle between 7.00 to 9.00 am. Temperature, $\mathrm{pH}$, Turbidity, Chloride, Ammonia, Nitrate, Hardness, Solids, Oxygen, CO2, Iron and Fluoride were recorded. Standard methods were followed for various analytical procedures

Table No. 2. : Variations in physico-chemical parameters of water during Rainy and Winter seasons.

\begin{tabular}{|c|c|c|c|c|c|}
\hline \multirow[t]{2}{*}{ Sr. No. } & \multirow[t]{2}{*}{ Parameters } & \multicolumn{2}{|c|}{ Rainy Season } & \multicolumn{2}{|c|}{ Winter Season } \\
\hline & & July & August & October & November \\
\hline 1 & Physical appearance & Clear & Clear & Clear & Clear \\
\hline 2 & Odour & $\begin{array}{l}\text { No } \\
\text { smell }\end{array}$ & No smell & $\begin{array}{c}\text { No } \\
\text { smell }\end{array}$ & No smell \\
\hline 3 & Surface temperature $\left({ }^{\circ} \mathrm{c}\right)$ & 26.1 & 28.00 & 30.00 & 32.1 \\
\hline 4 & $\mathrm{pH}$ & 8.08 & 8.01 & 7.4 & 7.1 \\
\hline 5 & Hardness(as CaCo3) & 210.00 & 215.0 & 172.0 & 172.00 \\
\hline 6 & $\mathrm{DO}(\mathrm{ml} / \mathrm{L})$ & 5.8 & 5.2 & 4.3 & 4.1 \\
\hline 7 & FreeCo2(mg/L) & 3.00 & 3.7 & 6.00 & 6.2 \\
\hline 8 & Nature of Climate & calm & calm & calm & calm \\
\hline 9 & Water Colour & Slightly & Slightly & Slightly & Slightly \\
\hline 10 & $\begin{array}{c}\text { Atmospheric } \\
\text { Temperature }\left({ }^{\circ} \mathrm{C}\right)\end{array}$ & 20.00 & 20.03 & 27.01 & 30.01 \\
\hline 11 & Turbidity(N.T.U.) & 1.9 & 1.9 & 1.7 & 1.7 \\
\hline 12 & Chloride(as CI) & 30.00 & 38.02 & 40.0 & 40.00 \\
\hline 13 & Ammonia(free)(as N) & 0.06 & 0.06 & 0.04 & 0.04 \\
\hline 14 & $\begin{array}{l}\text { Ammonia(Albuminoid) } \\
\text { (as N) }\end{array}$ & 0.11 & 0.12 & 0.09 & 0.09 \\
\hline 15 & Nitrate (as No3) & 6.30 & 6.31 & 5.87 & 5.87 \\
\hline 16 & Total solids(mg/L) & 320.15 & 325.0 & 220.00 & 205.00 \\
\hline 17 & Iron(as Fe) & 0.132 & 0.140 & 0.123 & 0.130 \\
\hline 18 & Fluoride & 0.185 & 0.181 & 0.176 & 0.180 \\
\hline
\end{tabular}




\section{Result and Discussion:}

The data of Zooplankton summarized in Table No. 1 and seasonal variations of certain physicchemical characteristic of Lake Water during rainy and winter seasons are shown in Table No.2. The physico-chemical parameters are the main controller of the development of the zooplankton. All the hydrological parameters and the nutrient are direct correlated with the growth of the zooplankton. The ecological factors are acutely sensitive in aquatic ecosystem which makes the effect on production.

\section{Water Temperature:-}

Water temperature of lake generally depends upon the season and time. Temperature is one of the most important physical factors, which regulate natural process within the ecosystem. Atmospheric and surface water temperature vary from $20.00^{\circ} \mathrm{C}$ to $30.1^{\circ} \mathrm{C}$ and $26.1^{\circ} \mathrm{C}$ to $32.1^{\circ} \mathrm{C}$ respectively. Both these temperatures of KAAS lake vary considerably during different seasons, like rainy and winter. Temperature being the lowest in the month of July is highest in the month of November. Increased temperature is generally caused by increase in solar radiations. Maximum record of water temperature in November $\left(32.1^{\circ} \mathrm{C}\right)$ may also be attributed to highest load of suspended matter. Similarly, gradual reduction in sola illumination may explain the fall in both atmospheric and surface water temperatures from June to November *PH:-

The chemical factors like $\mathrm{PH}$, free $\mathrm{Co} 2$ and alkalinity showed only minor seasonal fluctuations. It was recorded and it appears reasonable to suggest that low phytoplankton population was responsible to decrease in pH(George 1961,zutshi 1976).

\section{*Dissolved Oxygen:-}

It is one of the important parameters for life in water bodies. Dissolved oxygen was found to be higher in rainy season $(5.2$ to $5.8 \mathrm{ml} / \mathrm{L})$ and lower in winter months. Winter decreased dissolved oxygen has also been worked out earlier by Sigh et. al.(1980) and Rao (1986) and it appears to be due to its grater solubility, reduces microbial-decomposition of dead organic matter.

\section{*Free Co2:-}

The amount of free $\mathrm{CO} 2$ ranged between 5.00 and $6.4 \mathrm{mg} / \mathrm{L}$, being higher in winter and lower in rainy months.Inverse relationship of dissolved oxygen and free $\mathrm{CO} 2$ was observed. Well known workers (Welch 1952,Hutchinson 1957 and Kadlec 1962) observed similar tren
The total number and development of zooplankton is totally related to the values of environmental parameters of lake water. The maximum number of zooplanktons was recorded in rainy season due to availability of varities of nutrients due to natural percolation of potable water and the productivity of zooplankton was found least in winter season due to increased temperature of the surface of the water. This indicates that production of the zooplanktons always shows the negative correlation with temperature. This is also true in case of phytoplanktons which was noticed by Yeragi (2005)and Patole (2010). The quantitative as well as qualitative values were high during rainy season only. It is also noticed that the productivity is directly related to the dissolved oxygen. In rainy season The temperature is decreased and the oxygen content is increased which is considered as a favorable condition for development of zooplankton. It is also observed that during rainy season the nitrate concentration becomes high which further accelerates the growth of zooplanktons. Temperature is an abiotic factor which only helps in regularizing the growth of the zooplankton. In the present investigation it was observed that total hardness and production of zooplankton are in positive correlation. The seasonal variation of number of zooplankton may be due to heavy inflow of percolation. According to literature it is clear that of portable water. Heavy rainfall affects the density of zooplankton because of the speedy water current. The present observations are due to continuous heavy rainfall in lake area.

Dissolved oxygen showed an inverse relationship with water temperature. This is probably due to two reasons. In winter temperature is increased as compare to rainy season. Hence rate of oxidation of organic matter in water increased and oxygen is consumed during process. Secondly, at higher temperature water has a lesser oxygen holding capacity and some oxygen is lost to the atmosphere (Rajendran Nair 2000). So, the present study reveals that the inverse relationship observed between the dissolved oxygen and temperature was similar to that observed by many workers (Ganapati 1943, Saha et. al. 1959)Singh(1960). Actually planktonic animals in freshwater are dominated by three major groups, the rotifers and two subclasses of Crustacea, the cladocera and the cope-pods (Wetzel, 1983). But in the present study, a few more groups were also recorded. Fifteen species of Zooplankton belonging to 7 groups namely protozoa, porifera, 
Cladocera, Ostracoda, Arthropoda, Mollusca, Amphibia and fishes were recorded in KAAS lake during rainy and winter month.

The group protozoa was represented in the lake by four species namely paramecium caudatum Euglena, Vorticella companula etc. and other groups are summarized in Table No.1. among the total zooplanktonic organisms, the protozoans are shows maximum number during rainy season. The low population of group Cladocera was recorded in the rainy season but its number is increased during winter. It may be due to low temperature and other physicchemical factors of the aquatic bodies. It can be said that the winter peak of this population workers supported by Pahwa and Mehrotra(1996), while Govind (1969) and Das and Shrivastav(1956) observed winter maxima in tropical water.

But, generally quantitative analysis of zooplankton during winter shows lower density than that of the rainy season. The decrease in the zooplankton population may be attributed to the high temperature. Welch(1952) also reported that quantitatively, the plankton are likely to be less in tropical inlandwaters than in temperate waters.The fall in density of zooplankton during winter months may also be due to the decrease in thenutrients and phytoplankton population.

The results of present investigation obviously indicate higher number of zooplankton during rainy season and their stabilization during post rainy period and futher decline during winter. The above results and discussion clearly showed that the development and growth of the zooplankton is correlated to the values of environmental parameters.

\section{Acknowledgement:}

We wish to thank to Sou. Shubhangi Gawde, Secretary, Shri Swami Vivekan and Shikshan Sanstha, Kolhapur, Chief Executive Principal Shri Abhaykumar Salunkhe, Chairman UGC New Delhi and Principal Dr. Anil Patil, S.M. Dr. Bapuji Salunkhe College, Miraj.

\section{References:}

1. Babu, K.N., Yeragi S.G. 2001:Indian, J., Invert. Zool. Aquas. Bio., 5(1); 28-33.
2. Das, S.M. and Shrivastava,V.K. 1956: Proc. Nat. Acad. Sci., 26B(4); 243-253.

3. Ganapati, S.V. 1943: Proc.Ind. Acad.Sci.., $17 ; 41-59$.

4. George, M. G. 1961 :Curr. Sci..,30(7); 268269.

5. Govind, B. V. 1969: Proc.Sem.Ecol.,27-29.

6. Hutchinson,G.E. 1957:A Treatise on limnology.Vol.1.,John Wiley and Sons, New York,London;1015pp.

7. Kadlec,J.A. 1962: Ecology, 43(2); 267-281.

8. Pahwa, D. V. and Mehrotra, S.N. 1966 :Proc. Nat.Acad.Sci.,India,36(2); 157-189.

9. Patole, V. M. 2010; ph.D. Thesis, University of Mumbai.

10. Rajendran Nair, M.S. 2000. Recent Advances in freshwater Biology.

11. Rao,K.J. 1986: Proc.Nat. Symp.Fish and Env., 96-102.

12. Saha,K.C.,Sen D.P. and Sen Gupta,I.C. 1959 :Sci. Cult.,24(3);216-2 18.

13. Singh, R. K., Srivastava, N. P. and Desai, V.R. 1980: J. Inland fish Soc., India, 12(1).

14. Welch, P. S. 1952: Limnology.McGraw Hill Book Co.,New York,Pp. 539.

15. Wetzel, R.G. 1983.LimnologySaunders college Publ., New York.P.53.

16. Yeragi, S. G. 1997:Bio.Research Journal, Vol.1,46-53.

17. Yeragi,S.G.and Yeragi S.S. 2005 :J.Nocton 17(2) ;389-391.

18. Zutshi,D.P. 1976: Mem.Lgt.Ital.Indrobiol., $\underline{33}$;223-256. 